\title{
A Study on the Strategies of Improving the Efficiency of College English Classroom Bing Zhang
}

\author{
University of Foreign Language Teaching Ministry, Baicheng Normal college \\ JiLin Baicheng, China \\ liweiliwei77@163.com
}

Keywords: College English; Classroom efficiency; Flip classroom

\begin{abstract}
The effective promotion of college English classroom teaching is one of the hot issues in the study of educational theory in recent years. This paper analyzes the strategies of improving the efficiency of college English classroom from the aspects of changing the educational idea, strengthening the classroom subject and optimizing the teaching methods. Elaborated.
\end{abstract}

\section{Introduction}

In recent years, how to effectively improve the efficiency of college English classroom teaching has become one of the hot issues in educational theory research. With the implementation of educational curriculum reform in our country, effective teaching research has been paid more and more attention. The main body, the optimization of teaching methods and so on, to improve the efficiency of college English classroom strategy to explore ${ }^{[1]}$.

\section{Classroom Teaching More Targeted}

College English classroom teaching is a multi-level, multi-functional, comprehensive use of various sensory activities, teaching and learning is a two-way effect of the complex and meticulous process. In theory, the level of interpersonal communication in English classroom teaching can be divided into: interactive interaction, parallel interaction and downlink interaction. Teachers should be based on the teaching process to constantly improve and enrich the course content ${ }^{[2]}$, but also to be good at digging a variety of curriculum resources and to integrate, so that it is consistent with the teaching content and expand beyond the classroom. Therefore, the teaching methods and activities designed to take into account the interests of students and interest in order to teach each other. In general, the distinctive feature of college English classroom teaching is the diversification of teaching objectives. Not only through the college English classroom teaching to impart language knowledge, training students language skills ${ }^{[3]}$. More important is to cultivate students how to carry out independent learning and inquiry. Some teachers believe that the development of English learning interest is a secondary school teacher, the main task of university teachers is to develop students' English language skills. Therefore, only to improve the English classroom teaching should improve the students' language quality, cultural quality, thinking ability, self-learning ability, ideological and moral qualities and psychological adjustment ability in various environments as the basic goal, and take into account the knowledge, skills and spirit Three goals. So as to the students 'mental training and the improvement of students' scientific way of thinking have an important role in making students both language literacy and humanistic accomplishment ${ }^{[4]}$.

\section{The Use of Modern Teaching Ideas and Teaching Methods to Enhance the Effectiveness of Classroom Teaching}

With the development of Internet technology, educational means has also undergone a fundamental change, on the one hand, the Internet involved, greatly enriched the content of classroom teaching, on the other hand, the Internet closer to the distance between teachers and students, Classroom teaching effect has played a great help. "Flip classroom", micro class, Mu class these new forms of 
modern teaching came into being, "flip classroom" to improve the quality of classroom teaching and teaching interest, to stimulate students to participate in learning class enthusiasm. In the past, the teacher asked the teachers to select the key points and difficult points to be explained on the basis of the previous teaching, and combine the new knowledge with the original knowledge ${ }^{[5]}$, use the video and audio and video to enhance the students' autonomous learning ability, so as to achieve the ultimate goal of imparting knowledge, Meet the needs of different students in the classroom learning. In addition, the flip classroom requires teachers to respect the views of students, giving students scientific guidance to help them find ways to learn to improve their learning quality. Turn the classroom more emphasis on the exchange between teachers and students, for example, teachers in the use of multimedia technology teaching, the need to design a good interaction with students, enrich the way students participate in classroom learning. Students in the classroom can also use the mobile phone, computer and other tools to communicate with teachers, communicate with the teacher's feelings ${ }^{[6]}$, to find their own learning process deficiencies, and timely correction to improve the quality of classroom learning for their future work, learning provide help. Therefore, college English teachers in the teaching of the classroom to do the relevant work in the use of Internet technology at the same time enhance their professional quality, so that students feel the charm of English knowledge, enhance their listening, speaking, reading and writing skills to help teachers Better completion of college English classroom teaching tasks.

\section{Use of Modern Educational Ideas and Teaching Methods to Stimulate Students' Interest in Learning}

First of all, the network teaching means to create an indirect interaction between teachers and students learning environment, this learning environment, effectively reducing the students because of the direct face of teachers and may bring tension. Therefore, the teacher can be part of the previous classroom teaching content, on the campus network, as a translation teaching module for students to learn. In addition, teachers can also plan to increase the difficulty of practice ${ }^{[7]}$, to strengthen students of the Anglo-American culture, cross-cultural communication and other aspects of understanding, broaden their horizons. And students can read their English and Chinese articles on campus, students to translate their own, and then follow the original writing style, and gradually improve their reading, translation and writing level.

Second, the colleges and universities can directly use the teaching materials supporting CD-ROM. However, due to the students, equipment and other specific circumstances are not the same, and supporting CD-ROM mostly lack of systematic translation of teaching content, so teachers should be produced due to school multimedia courseware is necessary. The production of multimedia courseware should be based on the teaching objectives, the teaching process, the students 'knowledge level, the teaching content and the teaching media, and the principle of interactivity to cultivate students' autonomous learning ability to ensure that students of different levels get the translation ability Full training and improvement. According to the design of the translation of teaching modules, to make full use of pictures, sound, animation and even video images of the students to form a variety of sensory stimulation of the brain, the abstract content of the visualization, so many difficult to understand the translation theory becomes lively and interesting ${ }^{[8]}$. It is necessary to summarize and explain the commonly used methods and techniques of English and Chinese translation, and to supplement the Chinese culture and western social and cultural common sense related to sentences, paragraphs and articles, so that students can master the basic common sense of translation. Teachers can design multiple links for students at all levels, in the classroom by the teacher or students choose their own translation content, is conducive to improving the traditional English classroom atmosphere, is conducive to creating a lifelike foreign language environment, increase the learning process of learning ingredient.

Finally, the network provides a powerful search function, so that students can efficiently retrieve and access the campus online translation material library. So that students become the center, if they are medical students, you can choose medical materials for translation exercises; if they are interested in science and technology, you can practice science and technology translation. So that 
students can choose according to their own professional and hobbies and other different translation exercises, so that self-learning become a reality. Moreover, the interactive function of the network provides students with a more open interactive dialogue environment, so that teachers and students as well as students and students in the extracurricular timely communication. On the one hand, teachers can grasp the practice of students in a timely manner, and students can "hand" type of guidance; can also be found in the student translation exercises in the typical problem and spread to all students to watch, so as to effectively ensure the effectiveness of students and practice The In addition, the English teaching resources in the network environment are rich, the process is open, the form is diverse, which creates a better language learning environment for the students and can help the students to study for life. This teaching model is precisely adapted to the requirements of humanistic education and quality education.

\section{To Enhance Students' Subjective Consciousness and Actively Participate in Classroom Teaching}

The teaching model from the "teacher center" into a "student center" to enhance students in the classroom teaching of the dominant position, student-centered teaching model, the need for teachers from the student point of view, a clear purpose of learning, good teaching design, To take a flexible and diverse forms of classroom teaching, change the boring classroom atmosphere, play a student learning subjective initiative, to establish and mobilize students, and actively participate in the classroom activities. Teaching methods and teaching design to consider the interests and hobbies of students, the use of "language games", "situational performances" and other activities, to increase teacher and student interaction, active classroom atmosphere, so that students learn to interact to enhance English language skills. For example: in the classroom teaching can be used in group activities, role-playing and task-based teaching and other forms, so that students in cooperation with each other to improve the interest and ability to learn English, teachers to allow students to fully express their views on society and life, Of the content, not just the form of speech and grammar is correct or not, really do the cultivation of students' emotions and values. Using multi-level, classification teaching method ${ }^{[9]}$.

\section{Change the Teaching Philosophy, From the Transfer of Theoretical Knowledge to Cultivate Ability to Change}

The purpose of improving classroom efficiency is to improve students' practical ability as soon as possible. So that students benefit, because the master of the English skills, and thus more effectively stimulate interest in learning and improve the efficiency of classroom teaching, which requires teachers to change the teaching philosophy, the traditional teaching to teach the main theoretical knowledge, students are often trained "This is the question machine," the face of boring and practical function is not strong theoretical teaching model, students naturally easy to lose interest in learning, so this requires our college English teachers to change the traditional classroom teaching concept, change theory professor, To cultivate students practical ability to change, so that students benefit from the students get the skills at the same time, get the motivation to learn to participate in classroom activities, will naturally improve classroom efficiency. To achieve this goal, in the classroom, teachers need to insist on the completion of the task by the students. In explaining the text, the language point, are cited is not made, training students to independently analyze the problem, the ability to solve the problem. Usually, encourage students to grab the teacher in front of the answer. While carrying out a large number of training at the same time, pay attention to cultivate the correct learning methods, combined with the text content, organizational role performances. There are a lot of stories in college English intensive textbooks. The wonderful pieces of the text make the students perform by playing the role, so that the teaching form is lively and interesting, which can deepen the students' understanding of the text. You can also use the form of group communication, so that students communicate with each other information and ideas, can take turns in the form of speech. Which will mobilize the enthusiasm of students, exercise their 
thinking ability and the practical application of language will play a positive role in promoting. But also can use the application of style writing, simulation site recruitment, oral English and other forms of competition to improve the level of college students in English, so as to achieve the purpose of improving the efficiency of college English classroom ${ }^{[10]}$.

\section{Conclusion}

To sum up, to improve the college English classroom teaching effect is a long-term, step by step process, this article from the transformation of educational philosophy, strengthen the classroom body, optimize the teaching methods and other four aspects of improving the efficiency of college English classroom strategy to try and to sum up.

\section{References}

[1] Cognitive content engagement in content-based language teaching. Stella Kong,Philip Hoare. Language Teaching . 2011

[2] Resesarch Perspectives on English for Academic Purposes. . 2005

[3] Investigating the academic English language target needs of undergraduates at the Faculty of applied science at Al-Aqsa University:Students'Perceptions. Abdelgawad Ahmed Alastal,Munir Shuib. The Asian ESP Journal . 2012

[4] English for Specific Purposes in the EFL context:A survey of student and faculty perceptions. Tsao,Chia-hsiu. The Asian ESP Journal . 2011

[5] Three Steps to Developing a Successful Largescale ESP Pro-gram in Asia. Anthony L. 3rd International Conference on English for Specific Purposes in Asia . 2011

[6] Motivation for achievement: Past, present, and future. Schunk,D. H. Issues inEducation . 2000

[7] Content-based College ESL Instruction. Kasper L. Journal of Women s Health . 2000

[8] "BICS and CALP:Empirical and Theoretical Status of the Distinction.". Cummins,J. Encyclopedia of Language and Education. Part2,Part5 . 2008

[9] Distance learning: Principlesforeffective design, delivery, and evaluation. Mehrotra, M,Hollister, D,McGahey, L. . 2001

[10]CALL Dimensions: options and issuesincomputer-assisted language learning. Levy, Mike, Stockwell Glenn. . 2006 